\title{
Quantitative Interactor Screening with next- generation Sequencing (QIS-Seq) identifies Arabidopsis thaliana MLO2 as a target of the Pseudomonas syringae type III effector HopZ2
}

Jennifer D Lewis ${ }^{1,3}$, Janet Wan ${ }^{1}$, Rachel Ford ${ }^{1}$, Yunchen Gong², Pauline Fung ${ }^{2}$, Hardeep Nahal ${ }^{2}$, Pauline W Wang ${ }^{1,2}$, Darrell Desveaux ${ }^{1,2^{*}+}$ and David S Guttman ${ }^{1,2^{*}+}$

\begin{abstract}
Background: Identification of protein-protein interactions is a fundamental aspect of understanding protein function. A commonly used method for identifying protein interactions is the yeast two-hybrid system.

Results: Here we describe the application of next-generation sequencing to yeast two-hybrid interaction screens and develop Quantitative Interactor Screen Sequencing (QIS-Seq). QIS-Seq provides a quantitative measurement of enrichment for each interactor relative to its frequency in the library as well as its general stickiness (non-specific binding). The QIS-Seq approach is scalable and can be used with any yeast two-hybrid screen and with any nextgeneration sequencing platform. The quantitative nature of QIS-Seq data make it amenable to statistical evaluation, and importantly, facilitates the standardization of experimental design, data collection, and data analysis. We applied QIS-Seq to identify the Arabidopsis thaliana MLO2 protein as a target of the Pseudomonas syringae type III secreted effector protein HopZ2. We validate the interaction between HopZ2 and MLO2 in planta and show that the interaction is required for HopZ2-associated virulence.

Conclusions: We demonstrate that QIS-Seq is a high-throughput quantitative interactor screen and validate MLO2 as an interactor and novel virulence target of the P. syringae type III secreted effector HopZ2.
\end{abstract}

Keywords: Next-generation sequencing, yeast two-hybrid, high-throughput screening, Arabidopsis, Pseudomonas syringae, type III effector, MLO2, HopZ

\section{Background}

The Gram-negative bacterial pathogen Pseudomonas syringae uses a type III secretion system (T3SS) to translocate type III effector (T3SE) proteins into the cytoplasm of plant cells. The primary function of these T3SEs is believed to be the suppression of plant immunity [1-5]. Some plant hosts are able to respond to this challenge via effector-triggered immunity (ETI), a defense response that is elicited when a plant resistance (R) protein recognizes a specific effector protein either through

\footnotetext{
* Correspondence: darrell.desveaux@utoronto.ca; david.guttman@utoronto.ca + Contributed equally

'Department of Cell and Systems Biology, University of Toronto, Toronto, ON, M5S 3B2, Canada

Full list of author information is available at the end of the article
}

direct interaction, or indirectly via the action of the T3SE on its host targets [6,7]. The pathogen may respond by acquiring a new effector protein to suppress this recognition or by diversifying away from recognition $[7,8]$. Thus, the pathogen and host each endeavor to gain the upper hand, resulting in a co-evolutionary arms race.

There are $\sim 60$ T3SE families identified in $P$. syringae, yet a majority of these remain functionally uncharacterized. A key to ascribing functions to these virulence proteins will be the identification of their host target proteins. In addition, since many T3SEs have evolved to suppress plant immunity, they can be used as probes to identify important components of resistance signaling pathways.

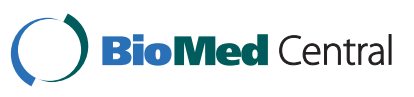

() 2012 Lewis et al; licensee BioMed Central Ltd. This is an Open Access article distributed under the terms of the Creative Commons Attribution License (http://creativecommons.org/licenses/by/2.0), which permits unrestricted use, distribution, and reproduction in any medium, provided the original work is properly cited. 
The HopZ family of T3SE proteins is an evolutionary diverse family that is part of the YopJ T3SE superfamily found in animal and plant pathogens $[9,10]$. The HopZ family of $P$. syringae is composed of three distinct allele families (HopZ1, HopZ2 and HopZ3), while HopZ1 also has three closely-related allele sub-families (HopZ1a, HopZ1b and HopZ1c). HopZ1a is most similar to the ancestral HopZ allele and is recognized by the ZAR1 resistance protein in Arabidopsis [9,11,12]. Although closely related to HopZ1a, HopZ1b is only weakly recognized, and HopZ1c is not recognized in Arabidopsis [11]. HopZ2 and HopZ3 are more similar to YopJ superfamily members found in other phytopathogens and were likely acquired by $P$. syringae via horizontal gene transfer [9]. Both HopZ2 and HopZ3 have been demonstrated to enhance P. syringae growth on Arabidopsis [11,13]. Overall, the HopZ family displays remarkable functional diversification in Arabidopsis with members able to enhance bacterial virulence while others trigger ETI. Therefore, the targets of this T3SE family will likely include critical components of host immunity.

The yeast two-hybrid $(\mathrm{Y} 2 \mathrm{H})$ system is a powerful tool to query protein-protein interactions $[14,15]$. Although several modifications of this method have been developed, they all involve using a bait protein of interest to identify interacting prey proteins. In general, this can be done by using a bait to systematically test specific prey clones, or alternatively using a bait to identify interacting proteins from a pooled library of prey clones. The former method has been applied extensively in highthroughput fashion to generate high quality protein-protein interactome maps $[16,17]$; nevertheless, the coverage of these interactome maps is relatively low and is typically limited to model organisms, which have high quality libraries of cloned open reading frames (ORFs). If an ORF library is not available, a widely used alternative is to screen a cDNA library; however, this approach carries the ascertainment and representation biases associated with all cDNA library methods. Additionally, screening of these biased libraries is typically limited by the throughput that candidate interactors can be sequenced.

Recently, Vidal and colleagues have established a framework to generate and assess high-throughput $\mathrm{Y} 2 \mathrm{H}$ screens and established the first protocol for next-generation sequencing of protein-protein interactomes $[18,19]$. Their Stitch-seq method employs PCR to concatenate the sequences of putatively interacting bait and prey proteins so that they comprise a single amplicon for downstream next-generation sequencing [19]. PCR stitching is done via common priming sites located downstream of both the bait and prey sequences. Their protocol was specifically designed for $\mathrm{Y} 2 \mathrm{H}$ assays using
Gateway sequences and clones, but can be generalized to other vectors and a wide variety of interaction assays. While unquestionably promising, there are some potential limitations to this approach. The first relates to the size of the Stitch-seq concatenated amplicon, which is substantially larger than read lengths produced by current next-generation genome sequencers. As the authors note, in principle this obstacle can be overcome as read lengths improve or through paired-end sequencing, but the short reads generated by many next-gen sequencers may prove difficult to associate with a specific gene when working with random cDNA libraries generated from organisms with limited genomic resources. Another potential limitation arises from the long lengths of the stitched PCR products, which encompass the bait ORF, a linker, and the prey ORF, and the need for two rounds of PCR, which may result in PCR biases that influence the recovery of candidate interactors.

Here we describe Quantitative Interaction Screen Sequencing (QIS-Seq), which couples split-ubiquitin yeast two-hybrid screening with Illumina next-generation sequencing to rapidly identify interacting partners of a bait of interest. We employed this high-throughput and quantitative interactor screen to identify host targets of the HopZ family of T3SE proteins, and then demonstrate that these targets include components of plant innate immunity in plants. All members of the HopZ T3SE family (except for HopZ3) are membrane-associated $[11,20]$, and as such, we used the split-ubiquitin yeast two-hybrid screen that utilizes a membrane-associated bait protein [21] in order to enrich for physiologically relevant interactors. We used this approach to identify MLO2 as an interactor of HopZ2, and confirmed this interaction in vivo by bimolecular fluorescence microscopy (BiFC). MLO2 has a characterized role in powdery mildew resistance, but had not previously been shown to contribute to $P$. syringae growth. We demonstrate that MLO2 contributes to resistance against $P$. syringae in Arabidopsis and is required for HopZ2 virulence function.

\section{Results}

\section{Evaluation of the cDNA prey library}

Our cDNA prey library was commercially made (Norclone Biotech Laboratories, Ontario) from RNA extracted from uninfected 4-5 week old Arabidopsis rosettes, as well as plants infiltrated with a virulent pathogen (P. syringae pv. tomato DC3000, PtoDC3000), a non-virulent strain lacking the T3SS apparatus (PtoDC3000 $\Delta \mathrm{hrcC}$ ), and an avirulent strain translocating a T3SE recognized by an Arabidopsis $\mathrm{R}$ protein (PtoDC3000 with AvrRpm1, which is recognized by RPM1). Although it is common to amplify primary cDNA libraries after their initial construction, this step 
can potentially introduce representation biases that may influence the interactor screen. We amplified the primary library by semi-solid amplification as this method is believed to reduce overall amplification bias [22]. We first sequenced the primary and secondary cDNA prey libraries to assess representation and bias arising from the initial library construction and subsequent amplification. Amplified DNA was sequenced on an Illumina GA-IIx using standard protocols at the University of Toronto Centre for the Analysis of Genome Evolution and Function (CAGEF). Sequencing of the primary- and amplified libraries yielded $59.8 \mathrm{M}$ and $5.8 \mathrm{M}$ reads respectively, which read-mapped to $\sim 11 \mathrm{~K}$ Arabidopsis genes $(4,119 \mathrm{M}$ and $213 \mathrm{M}$ bases of data, Additional file $1)$. The cDNAs ranged from $\sim 40 \mathrm{nt}$ up to $\sim 2,800 \mathrm{nt}$, with most not being full length since they were generated by random hexamer priming (Additional file 2A, B). A scatterplot of the hits/locus for the two libraries revealed very high congruence $\left(R^{2}=0.96\right.$, Additional file $2 \mathrm{C}$ ), indicating that very little bias was introduced during the amplification process.

To further evaluate the range of genes represented in the library, we analyzed the gene ontology (GO) annotations of the cDNAs recovered (Figure 1A). Many biological processes were represented including metabolism, response to stress or stimulus, development, transport and signal transduction, although unknown was the most common (42\%). The subcellular localization of many of the cDNAs was also unknown; however, loci were identified in virtually every cellular compartment including $13 \%$ associated with membranes. Genes with known molecular functions included those involved in

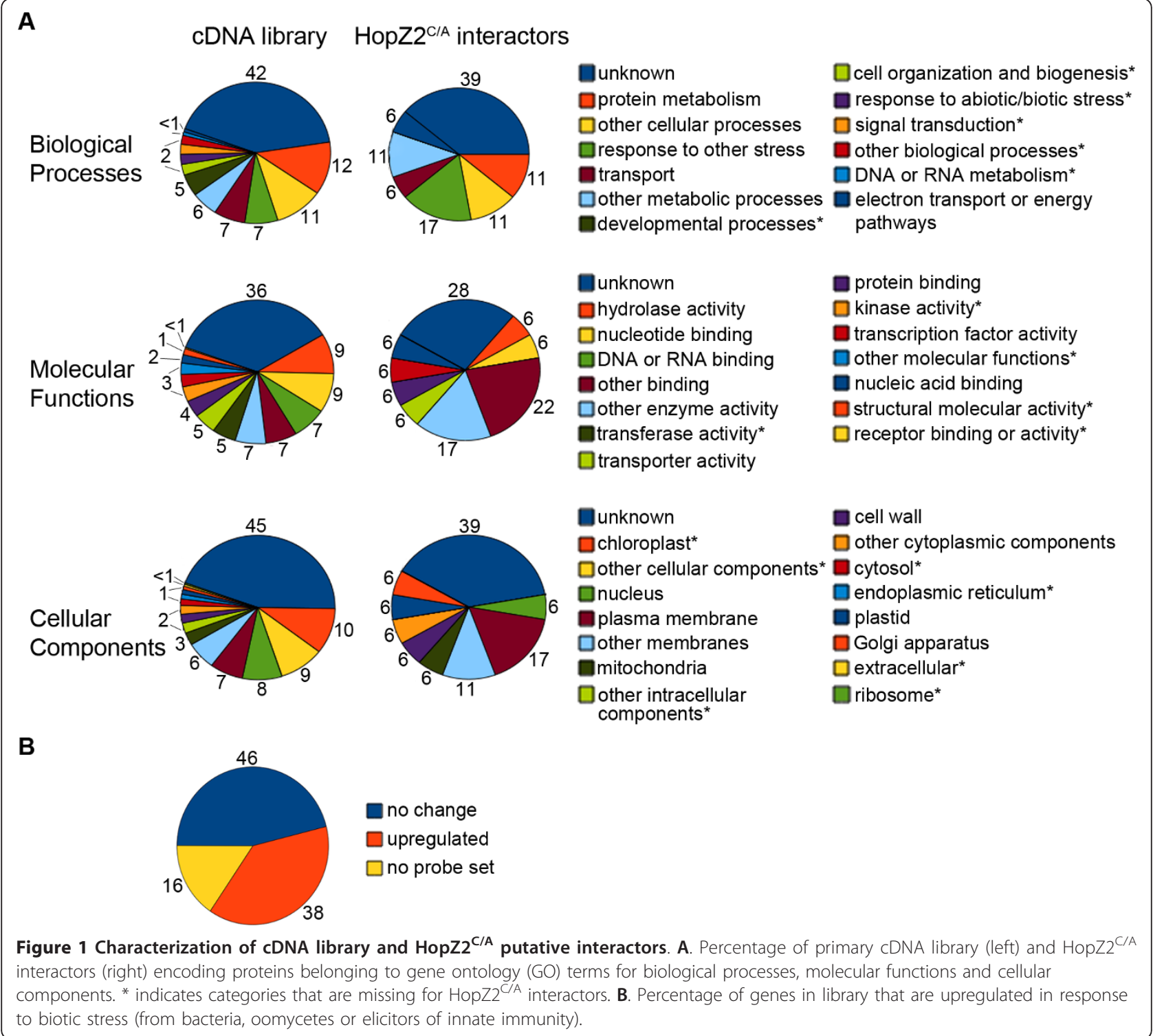


protein binding, hydrolase activity, nucleic acid metabolism, transcription factors, transporters, and kinases. We further examined publicly available microarray data available through the CAGEF Bio-Array Resource (BAR, http://bar.utoronto.ca, [23]) to determine whether loci represented in our library were differentially regulated in responses to biotic stress from bacteria ( $P$. syringae), oomycetes (Botrytis cinerea, Phytophthora infestans, Golonivomyces orontii), or elicitors of innate immunity (harpins, lipopolysaccharides, and an oomycete elicitor NPP1). 38\% of genes were upregulated more than 2-fold in response to biotic stress while $46 \%$ did not respond to biotic stress (Figure 1B). A further 16\% did not have probe sets to detect transcriptional changes arising from biotic stress. None of our library loci were downregulated in response to biotic stress.

\section{Quantitative Interaction Screen Sequencing (QIS-Seq)}

Since most members of the HopZ family of T3SE proteins are membrane-associated by myristoylation [11], we adapted the split-ubiquitin yeast two-hybrid system that was developed for transmembrane bait proteins (Figure 2A and Additional file 3) [21]. Based on membrane-association studies of K-Ras, we constructed a

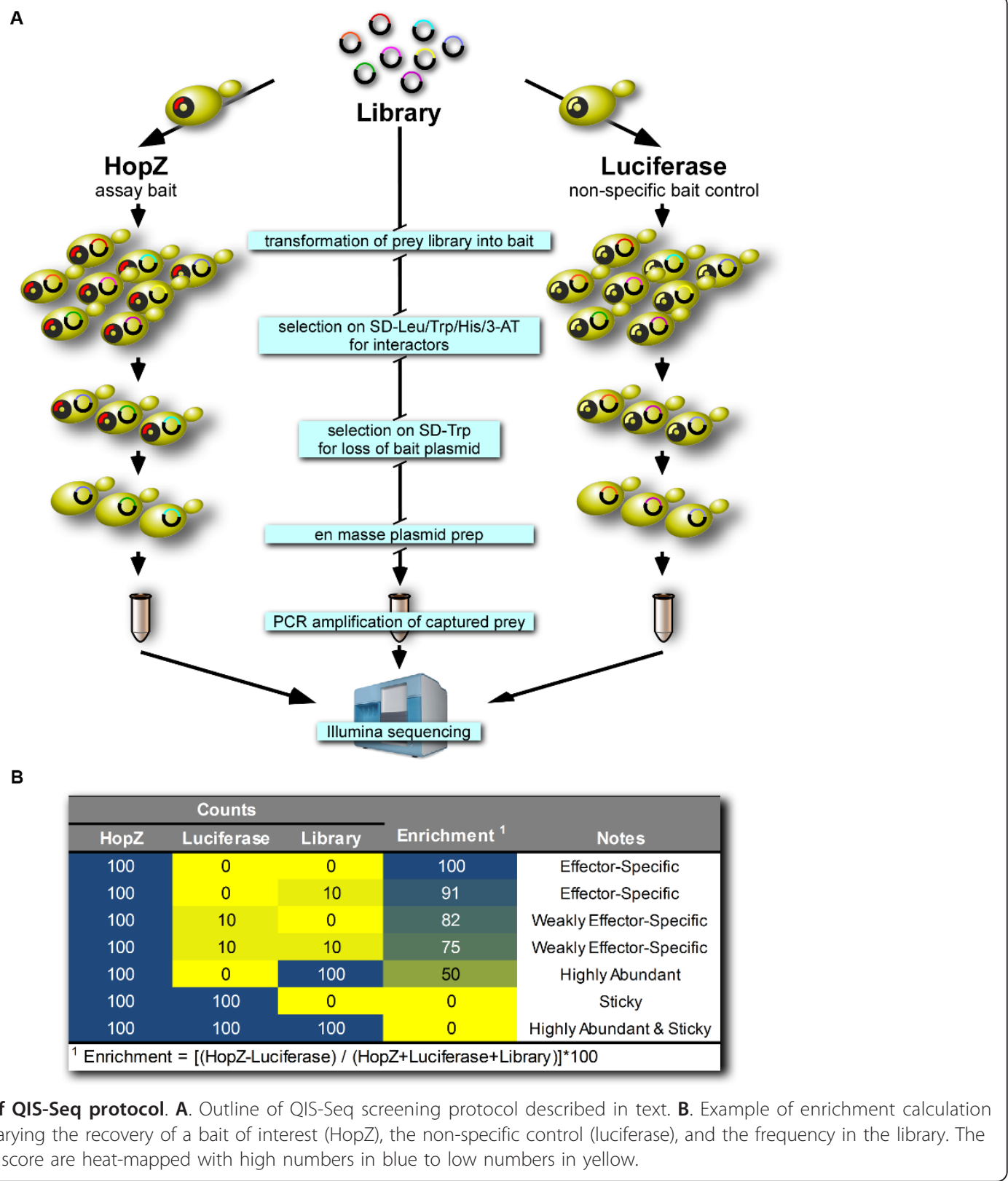


bait vector with a $\mathrm{C}$-terminal prenylation signal and polybasic sequence in order to stably associate the protein with membranes (Additional file 4) [24,25].

We screened the Arabidopsis prey library by cloning catalytic mutants of all five of the HopZ alleles, as well as the Arabidopsis $\mathrm{R}$ protein ZAR1 that recognizes HopZ1a into our membrane-tethered bait vector (Figure 2A,Additional files 3, 4). We used the catalytic mutants of the HopZ T3SEs in order to prevent processing of putative substrates and potentially stabilize transient interactions that would occur with the active enzyme. This method has been termed inactive catalytic domain capture (ICDC) and has proven successful for stabilizing enzyme-substrate interactions [26,27]. We also screened the prey library with HopF $2_{P t o}$, which is a P. syringae T3SE that is unrelated, both with respect to function and sequence, to the HopZ family, as well as luciferase as a non-specific protein control since it should not specifically interact with any Arabidopsis proteins. We transformed our baits of interest by lithium acetate/PEG transformation and screened them on plates with dropout media lacking histidine, one of the interaction reporter genes. Approximately 2000 colonies of each bait were collected and then restreaked twice on dropout media lacking tryptophan in order to preferentially retain the prey plasmid and lose the bait plasmid thereby reducing the complexity of the plasmid pool for next-generation sequencing [28]. The colonies were harvested en masse, digested with lyticase, and then plasmids were purified using alkaline lysis. Finally, the preyplasmid inserts were amplified with vector-specific primers using low-cycle PCR to reduce amplification bias and the PCR product was Illumina sequenced. Each bait provided 4.7 $\mathrm{M}$ to $33.6 \mathrm{M}$ quality reads (176 $\mathrm{M}$ to 2,544 $M$ bases of data, Additional File 1) which were readmapped to the Arabidopsis reference using Novoalign (http://Novocraft.com), which performs base-quality aware, global alignments with affine gap penalties using full implementation of the Needleman-Wunsch algorithm. The number of reads per Arabidopsis coding sequence were converted to reads per million in order to normalize across samples.

We then assessed for overall enrichment of each candidate interactor by scaling the number of hits observed between our bait of interest and each candidate interactor relative to the frequency of those candidates in the primary library. The candidates' general 'stickiness' was also assessed by the number of times it was recovered using luciferase, our non-specific bait protein. Specifically, enrichment was calculated as (T3SE-luciferase)/ (T3SE+luciferase+library) "100, where each term is scaled as the number of mapped-reads per million (Figure 2B). This enrichment measure scales from 0 to 100 with higher values corresponding to those candidate interactors that do not bind luciferase (are not sticky) and are rare in the library (Additional file 5).

\section{Functional analysis of HopZ2-interactors}

We elected to focus our initial functional study on HopZ2 because it can promote $P$. syringae growth in Arabidopsis and also since a preliminary analysis of the data provided the most interesting candidate interactors. Our enrichment analysis of HopZ2 ${ }^{\mathrm{C} 229 \mathrm{~A}}$ (hereafter HopZ2 ${ }^{\mathrm{C} / \mathrm{A}}$ ) interactors identified several highly overrepresented and specific candidate interactors (Table 1 and Additional file 5). HopZ2 $2^{\mathrm{C} / \mathrm{A}}$ interactors were enriched for membrane-associated proteins $(28 \%$ $\mathrm{HopZ2}^{\mathrm{C} / \mathrm{A}}$ vs. $13 \%$ cDNA library; Figure $1 \mathrm{~A}$ ) as well as proteins associated with responses to stress relative to the prey library (17\% HopZ2 ${ }^{\mathrm{C} / \mathrm{A}}$ vs. $7 \%$ cDNA library; Figure $1 \mathrm{~A})$. Based on our sequencing of the cDNA prey library, we could also assess the percent cDNA coverage of each HopZ2 $2^{\mathrm{C} / \mathrm{A}}$ interactor in the prey library. For functional analyses we focused on the HopZ2 ${ }^{\mathrm{C} / \mathrm{A}}$ interactors that had: (1) an enrichment value > 90\% (33 loci), (2) were represented by clones $>33$ amino acids in the cDNA prey library (ie. cDNA > 100 nucleotides) $(18 / 33$ loci) and (3) were specific to HopZ2 ${ }^{\mathrm{C} / \mathrm{A}}$ (i.e. not present with an enrichment score of $>50 \%$ in other baits tested) (11/33 loci). We hypothesized that these genes would include HopZ2 virulence targets and that their disruption would alter $P$. syringae growth.

We measured $P$. syringae growth in Arabidopsis lines carrying T-DNA insertions for each HopZ2 ${ }^{\mathrm{C} / \mathrm{A}}$ specific interactor to determine if the candidate HopZ2 interacting proteins played any role in $P$. syringae disease or resistance. We focused on interactors for which there were confirmed homozygous T-DNA insertion lines available and that were predicted to have the T-DNA insertion in an exon of the gene, and thus be more likely to interrupt the protein (5/33 loci, Table 1$)$. We assayed for changes in immunity by infiltrating the T-DNA insertion lines with the virulent pathogen PtoDC3000 and evaluating bacterial growth after three days. Insertions in genes At4g35750, At5g20700, At4g00430 and At1g68440, showed no difference in PtoDC3000 growth compared to the wild-type Col-0; however, an interruption in gene At1g11310 (line mlo2-7), encoding MLO2 showed a tenfold decrease in PtoDC3000 growth (Figure 3A). To further assess if this locus plays a role in resistance of Arabidopsis to PtoDC3000 we tested an additional TDNA insertion line in At1g11310 (mlo2-6, Figure 3B). Bacterial growth was reduced by approximately 10 -fold in mlo2-6 compared to Col-0 wildtype (Additional file $6 \mathrm{~A})$ indicating that the mlo2 mutation increases resistance to PtoDC3000.

The mlo2-11 (pmr2-1) mutant of Arabidopsis, which is a point mutant (D287N) in $M L O 2$ Figure 3B), was 
Table 1 Top HopZ2 ${ }^{\mathrm{C} / \mathrm{A}}$ Interactors

\begin{tabular}{|c|c|c|c|c|c|c|c|}
\hline Locus & $\begin{array}{c}\text { HopZ2 } \\
\text { rpm }^{1}\end{array}$ & $\begin{array}{l}\text { Luciferase } \\
\text { rpm }\end{array}$ & $\begin{array}{c}\text { Library } \\
\text { rpm }\end{array}$ & $\begin{array}{c}\text { HopZ2 } \\
\text { Enrichment }^{2} \\
\end{array}$ & $\begin{array}{c}\% \text { cDNA } \\
\text { Coverage }\end{array}$ & $\begin{array}{l}\text { Additional } \\
\text { Interactor }^{3} \\
\end{array}$ & $\begin{array}{c}\text { Library }^{4} \text { or T-DNA Line } \\
\text { Notes }\end{array}$ \\
\hline At5g20700* & 997.9 & 0 & 1.9 & 99 & 39 & & Exon \\
\hline At4g35450 & $9,335.5$ & 0 & 44.7 & 99 & 89 & & $5^{\prime}$ UTR \\
\hline At5g13860 & $2,620.7$ & 0 & 46.4 & 98 & 99 & & $5^{\prime}$ UTR \\
\hline At5g37600 & $2,531.3$ & 0 & 51 & 98 & 62 & HopF2, ZAR1 & \\
\hline At4g35750* & 538.7 & 0 & 12.2 & 98 & 33 & & Exon \\
\hline At3g55980 & $6,583.9$ & 0 & 189 & 97 & 59 & Z1b, HopF2, ZAR1 & \\
\hline At3g55410 & 2,789 & 0 & 86 & 97 & 32 & & ND \\
\hline At1g11310* & $1,693.2$ & 0 & 66.3 & 96 & 51 & & Exon \\
\hline At3g04790 & $1,297.5$ & 0 & 56.4 & 96 & 100 & HopF2 & \\
\hline At2g34470 & $3,792.6$ & 1.5 & 184 & 95 & 100 & ZAR1 & \\
\hline At4g27520 & $1,945.6$ & 0 & 101.2 & 95 & 71 & Z3, ZAR1 & \\
\hline At3g23890 & 0.6 & 0 & 0.03 & 95 & 2 & $\mathrm{Z3}$ & Short \\
\hline At3g17820 & 0.6 & 0 & 0.03 & 95 & 7 & & Short \\
\hline At2g14720 & $2,792.8$ & 0.5 & 161 & 95 & 37 & HopF2 & \\
\hline At2g05160 & $4,214.3$ & 7.8 & 265.4 & 94 & 65 & & ND \\
\hline At1g66200 & 1.9 & 0 & 0.14 & 93 & 6 & ZAR1 & Short \\
\hline At1g01930 & 89.7 & 0.3 & 7.1 & 92 & 60 & $\mathrm{Z1b}$ & \\
\hline At1g24706 & 195.6 & 0 & 18.4 & 91 & 13 & $\mathrm{Z1C}$ & \\
\hline At1g68440* & 185.8 & 0 & 18.2 & 91 & 21 & & Exon \\
\hline At1g08980 & $7,293.2$ & 8 & 701 & 91 & 100 & Z1a, HopF2 & \\
\hline At4g00430* & $3,886.5$ & 15.3 & 372.9 & 91 & 100 & & Exon \\
\hline At2g04140 & 0.32 & 0 & 0.03 & 90 & 4 & ZAR1 & Short \\
\hline At1g04170 & 0.32 & 0 & 0.03 & 90 & 6 & $\mathrm{Z3}$ & Short \\
\hline At5g67380 & 0.32 & 0 & 0.03 & 90 & 6 & & Short \\
\hline At2g26110 & 0.32 & 0 & 0.03 & 90 & 4 & & Short \\
\hline At5g54890 & 0.32 & 0 & 0.03 & 90 & 4 & $\mathrm{Z3}$ & Short \\
\hline At5g25110 & 0.32 & 0 & 0.03 & 90 & 3 & Z1c & Short \\
\hline At2g22840 & 0.32 & 0 & 0.03 & 90 & 5 & $\mathrm{Z1C}$ & Short \\
\hline At1g48280 & 0.32 & 0 & 0.03 & 90 & 5 & Z1c & Short \\
\hline At3g23390 & 0.32 & 0 & 0.03 & 90 & 19 & Z1c, HopF2, ZAR1 & Short \\
\hline At5g24010 & 0.32 & 0 & 0.03 & 90 & 3 & Z1c & Short \\
\hline At3g55940 & 0.32 & 0 & 0.03 & 90 & 2 & Z1b, Z1c, Z3, HopF2 & Short \\
\hline At1g66620 & 0.32 & 0 & 0.03 & 90 & 5 & Z1a, Z1c, Z3 & Short \\
\hline
\end{tabular}

${ }^{1} \mathrm{rpm}=$ reads per million

${ }^{2}$ Enrichment $=[(\text { HopZ-Luciferase }) /(\text { HopZ+Luciferase+Library })]^{*} 100$

${ }^{3}$ See Additional file 5 for enrichment data with other baits.

4 "Short" indicates that the prey cDNA library clone was less $100 \mathrm{nt}$ in length. ND $=$ not determined.

5 "Exon" \& " 5 ' UTR" indicate that the T-DNA insertion is in either the exon or the 5 ' UTR.

*Tested for increased or decreased bacterial growth

previously identified in a genetic screen for mutants showing enhanced resistance to powdery mildew $[29,30]$. However, unlike mlo2-6 and mlo2-7, but consistent with the previous report [29], mlo2-11 (pmr2-1) does not exhibit any significant change in P. syringae growth compared to Col-0 (Additional file 6B).

\section{HopZ2 targets Arabidopsis MLO2}

We further examined whether knocking out MLO2 would affect the virulence advantage normally conferred by HopZ2 when carried by the weak Arabidopsis pathogen $P$. syringae pv. cilantro 0788-9 (Pci0788-9; [11]). We infiltrated Arabidopsis Col-0 and mlo2-7 leaves with Pci0788-9 carrying either an empty vector (EV) or HopZ2. As previously observed [11], HopZ2 conferred a virulence advantage to Pci0788-9 in Col-0, but the HopZ2-associated virulence advantage was compromised in the mlo2-7 line (Figure $3 \mathrm{C}$ ), indicating $\mathrm{MLO} 2$ is required for HopZ2-associated virulence.

To determine whether HopZ2 and MLO2 interact in planta, we created fusions between both $\mathrm{HopZ2}^{\mathrm{C} / \mathrm{A}}$ and MLO2 to the N- or C-terminus of YFP (nYFP or cYFP) 


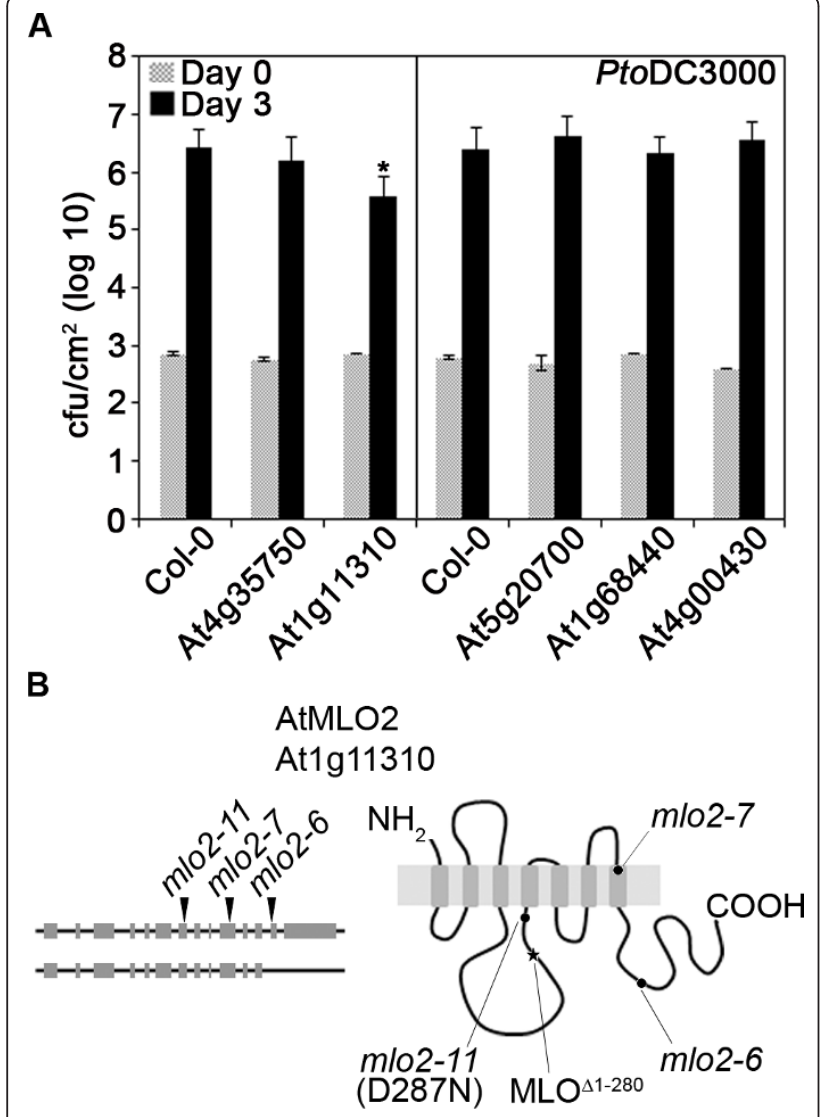

C

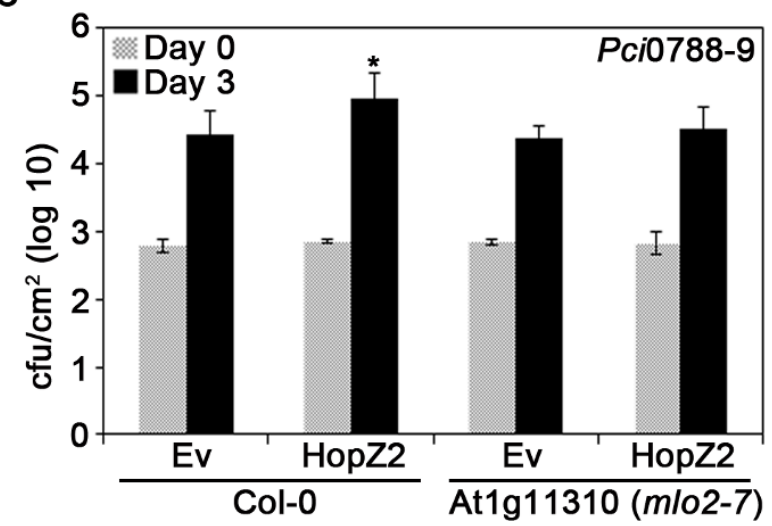

Figure 3 Disruption of $\mathrm{MLO} 2$ compromises $P$. syringae virulence. A. The virulent pathogen PtoDC3000 was pressureinfiltrated into the leaves of Arabidopsis Col-0 or T-DNA insertion lines in putative interactors of HopZ2 ${ }^{\text {/ }}$ A. An insertion in At1g11310 (m/o2-7) results in increased resistance to PtoDC3000. * indicates significant difference from Col-0 by Fisher's Protected Least Significant Difference (PLSD) test. Error bars indicate one standard deviation of the mean. B. Schematic showing the MLO2 gene and protein structure with the point of insertion for the T-DNA insertion lines and the point mutant. The left side shows the gene with introns represented as lines and exons represented as boxes. MLO2 has two splice forms which differ at the $3^{\prime}$ end of the gene. The right side shows the transmembrane structure of the MLO2 protein. mlo2-6 and mlo2-7 are T-DNA insertion lines while mlo2-11 is a point mutant. MLO $\mathrm{O}^{\Delta 1-280}$ indicates the clone identified in the CDNA library screening. $\mathbf{C}$. The weak pathogen Pci0788-9 carrying the empty vector (Ev) or HopZ2 was pressure-infiltrated into the leaves of Arabidopsis Col-0 or mlo2-7. Statistical significance was determined as stated in part $A$

in a glucocorticoid-inducible conditional expression vector. We used a partial clone of MLO2 beginning at amino acid residue 281 of the full-length protein and containing the $4^{\text {th }}, 5^{\text {th }}, 6^{\text {th }}$ and $7^{\text {th }}$ transmembrane domains as well as the $\mathrm{C}$-terminal cytosolic tail of the protein $\left(\mathrm{MLO}^{\triangle 1-280}\right)$, corresponding to the fragment of the clone in our cDNA prey library (Figure $3 \mathrm{~B}$ ).

We infiltrated equivalent optical densities of Agrobacterium carrying HopZ2::nYFP, HopZ2 $2^{\mathrm{C} / \mathrm{A}}:$ :nYFP or HopZ1c::nYFP with MLO2 $2^{\Delta 1-280}:: c Y F P$, as well as the reciprocal combination. We used HopZ1c as a negative control because it did not interact with MLO2 in our yeast two-hybrid screening (Additional file 5, data not shown). Protein expression was induced by spraying the plants with dexamethasone post-infiltration. 72 and 96 hours after dexamethasone application we observed bright fluorescence in leaf sections co-infiltrated with HopZ2::nYFP or HopZ2 ${ }^{\mathrm{C} / \mathrm{A}}:: \mathrm{nYFP}$ and $\mathrm{MLO}^{\Delta 1-280}:$ : cYFP, as well as the reciprocal combination (Figure 4; Additional file 7A). No fluorescence was observed with HopZ1c::nYFP and MLO2 ${ }^{\Delta 1-280}:: c Y F P$ (or the reciprocal combination) at these time points. The interaction between $\mathrm{MLO}^{\triangle 1-280}$ and HopZ2 localized to the

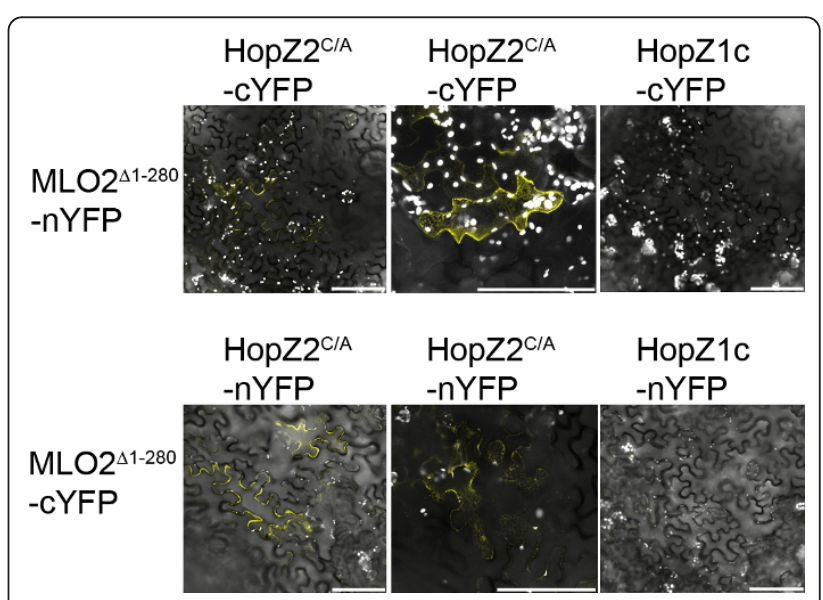

Figure $4 \mathrm{HopZ2}^{\mathrm{C} / \mathrm{A}}$, but not HopZ1c, interacts with $\mathrm{MLO}^{\Delta 1-280}$ in planta by bimolecular fluorescence microscopy. Agrobacterium carrying HopZ2 ${ }^{\mathrm{C} / \mathrm{A}}:$.nYFP or MLO2 $2^{\triangle 1-280 . .}$. YYFP (or the reciprocal combination) were mixed at equivalent optical densities and pressure-infiltrated into the leaves of $\mathrm{N}$. benthamiana. Expression of the proteins was induced by $20 \mu \mathrm{M}$ dexamethasone. Sections of leaf tissue were imaged with a Leica SP5 confocal scanning microscope 72-96 hours post-induction. The close-up images in the second column show the reticulate pattern reminiscent of the endoplasmic reticulum. The scale bar indicates $100 \mu \mathrm{m}$. 
periphery of the cell suggestive of the plasma membrane as well as reticulate network reminiscent of the endoplasmic reticulum (ER; Figure 4). This localization pattern was also observed when an MLO2 $2^{\Delta 1-280}:$ :YFP fusion was transiently expressed in $N$. benthamiana (Additional file 7B).

\section{Discussion}

We developed QIS-Seq, a quantitative, high-throughput yeast two-hybrid screening protocol combined with Illumina next-generation sequencing, to identify putative interacting proteins with the HopZ family of type III effector proteins. QIS-Seq provides many significant advances over traditional interactor screens: (1) it eliminates the need to individually sequence each interacting colony while at the same time vastly increasing the number of candidates interrogated; (2) the results are quantitative and therefore amenable to statistical analysis; (3) the method explicitly evaluates the enrichment of each interactor relative to both its presence in the prey library as well as its general (non-specific) stickiness; (4) sequencing of the prey library provides a hereto unprecedented ability to evaluate the cDNA library for complexity and completeness; (5) it is amenable to any type of yeast two-hybrid screen; (6) it is amenable to any type of next-generation sequencing; (7) it is completely scalable and therefore applicable to experiments run in a very small, multiplex format, to very large automated, high-throughput screens; and (8) the quantitative nature of the data also enhances the method's 'portability' among laboratories.

A number of these points are worth elaborating. The ability to interrogate putative interactors relative to their presences in the prey library (points 3 and 4) is particularly critical when not working with well-established model systems. One of the great benefits of next-generation sequencing is the ability to more easily study nonmodel systems. By definition, these systems have few established genomic resources, such as normalized cDNA libraries. The in silico normalization provided by QIS-Seq facilitates the use of any prey library, regardless of its means of preparation. For example, tissue, cell, age or stage-specific libraries could be rapidly constructed and tested without the need for tedious and sample consuming normalization steps.

Portability in the context mentioned in point 8 , means that standards can be established for experimental design, data collection, and data analysis, which will allow experimental results to be comparable among laboratories. Examples of such portability standards included the MIAME (Minimum Information About a Microarray Experiment) [31] and MIGS (Minimum Information about a Genome Sequence) specifications [32]. Another benefit of these standards is that it encourages the development of data repositories and meta-analysis tools such as the Bio-Array Resource [23] for microarray data.

A potential criticism of QIS-Seq is its cost-effectiveness, since the cost of next-generation sequencing is not trivial. Currently, it cost between US\$1000-US\$4000 for a single channel of Illumina next-generation data (depending on the specific protocol and platform). While we sequenced to quite high coverage in this proof-of-principle study, this depth is not generally required, and we found that 5 million reads were more than adequate. Since the current Illumina HiSeq2000 platform currently produces over 100 million reads per lane, it should be possible to multiplex as many as 20 samples per channel. Importantly, bar-codes can be directly incorporated onto the primers used to amplify the prey-plasmid inserts, thereby permitting the pooling of independent samples prior to Illumina sample prep. Early pooling of bar-coded samples means that only one sample prep is required for all pooled samples, and consequently, while the cost for a single channel of Illumina data may be US $\$ 2500$, the cost per sample (if multiplexing 20 samples per channel) would only be US $\$ 125$. This price is substantially less than the cost for Sanger sequencing 100 clones, and the cost will only continue to drop as the next-generation sequencing technology improves.

Since we had previously shown that HopZ2 confers a virulence advantage to $P$. syringae in Arabidopsis, we therefore rationalized that we could use HopZ2 as a probe for the identification of innate immunity components. By conducting QIS-seq screens on all members of the HopZ family, we were able to identify proteins that interact specifically with HopZ2. These HopZ2 interactors were enriched for membrane-associated proteins as well as proteins from genes induced during stress responses, including Arabidopsis MLO2. The lack of interaction between MLO2 and the other HopZ family members suggests that the HopZ family has diversified to target different host proteins.

MLO2 has seven transmembrane domains with an extracellular $\mathrm{N}$-terminus and an intracellular C-terminus and is localized to the plasma membrane [33]. HopZ2 is normally present at the plasma membrane and would be ideally localized to interact with MLO2 [11]. Our analysis identified a partial clone of MLO2 starting just prior to the fourth transmembrane domain and including the entire intracellular C-terminus (MLO2 ${ }^{\Delta 1-280}$; Figure $3 \mathrm{~B}$ ). Using MLO2 $2^{\Delta 1-280}$ in BiFC analyses, we demonstrated that HopZ2 and MLO2 interact directly in planta. However, the observed fluorescence complementation localized to a reticulate structure reminiscent of the ER as well as the plasma membrane. This localization was also observed with $\mathrm{MLO} 2^{\Delta 1-280}:$ YFP (Additional file 7B), 
suggesting that $\mathrm{MLO}^{\Delta 1-280}$ may be partially mislocalized.

The $M L O$ gene was first identified by map-based cloning in barley from mutants that were resistant to the powdery mildew fungal pathogen Blumeria (formerly Erysiphe) graminis f. sp. hordei (Bgh) [34]. However, mlo-based resistance in crop species has been employed by plant breeders for decades [35]. As in barley, Arabidopsis mlo 2 confers increased resistance to a powdery mildew fungal pathogen, Golonivomyces (formerly Erysiphe) orontii [30]. However, it has been reported (with data not shown) that $P$. syringae growth did not significantly differ in mlo2 compared to Col-0 [29,30]. Vogel and colleagues [29] evaluated symptom production in mlo2 (originally called $p m r 2$ ) point mutants when infiltrated or sprayed with PtoDC3000, while Consonni and colleagues [30] tested bacterial growth and symptom production from PtoDC3000 in a T-DNA insertion line (SAIL_878_H12; mlo2-5) that is inserted towards the end of the $6^{\text {th }}$ exon (Figure $\left.3 \mathrm{~B}\right)$. Our growth assays with PtoDC3000 in the mlo2-11 (pmr2-1) point mutant confirmed that it did not exhibit increased resistance to $P$. syringae (Additional file 6B). While mlo2-11 (pmr2-1), which has a $\mathrm{D} 287 \mathrm{~N}$ point mutation, in the intracellular loop between the third and fourth transmembrane domains [30], confers increased resistance to powdery mildew, it does not appear to be sufficient to confer increased resistance to $P$. syringae, suggesting that MLO2 differentially contributes to immunity against these distinct pathogens. In contrast, unlike Consonni and colleagues we did observe a significant decrease in PtoDC3000 bacterial growth in two independent Salk TDNA lines in the MLO2 gene (mlo2-6 and mlo2-7), although we did not test their T-DNA insertion line (mlo2-5). Our results suggest that MLO2 negatively contributes to resistance against P. syringae in Arabidopsis, and are consistent with the proposed role of MLO2 as a negative regulator of defenses against oomycete pathogens.

Previous work has shown that MLO is relocalized to a lipid raft-like domain in the plasma membrane upon pathogen attack [36]. MLO2 has also been shown to negatively regulate PEN1-dependent vesicular trafficking to regions of the plasma membrane associated with pathogen entry $[7,37,38]$. PEN1 is a syntaxin that has been associated with aberrant non-host resistance to the fungal barley pathogen $B g h$, and is likely part of a SNARE complex involved in vesicular trafficking of defense components [37,39]. When PEN1 is recruited to sites of pathogen attack, it contributes to the rapid formation of papillae, an important component of the innate immunity $[38,39]$. Our data in conjunction with the prior studies suggest that pathogens may stabilize MLO2 or cause its accumulation at the plasma membrane in order to suppress PEN1-dependent secretion of defense components.

There is precedence in the literature for $P$. syringae T3SEs to target negative regulators of plant immunity. The absence of RIN4 in rin4 rps 2 plants compromises plant immunity whereas RIN4 overexpression enhances immunity [40]. Interestingly, at least four unrelated T3SEs have been demonstrated to target RIN4, potentially to enhance its role as a negative regulator of plant immunity [40-44]. Plant vesicular trafficking pathways are also targeted by $P$. syringae T3SEs. The T3SE HopM1 induces the degradation of AtMIN7, an ARF guanine exchange factor (GEF) that is involved in vesicular trafficking [45]. Similarly, HopZ2 may stabilize MLO2 in order to prevent the secretion of defense components to the regions of pathogen attack.

\section{Conclusions}

Overall we have demonstrated that QIS-Seq provides a powerful new approach to identify protein interactions using next-generation sequencing. We used this approach to identify Arabidopsis MLO2 as a virulence target of the P. syringae T3SE HopZ2. Since HopZ2 (as well as other P. syringae T3SEs) is membrane localized we used the split-ubiquitin yeast two-hybrid system for interaction screening $[11,21,46]$. However, QIS-Seq is applicable to any sequencing-based yeast two-hybrid screening method. Furthermore, this approach can be applied to both ORF as well as cDNA libraries. Although we sequenced the interactors of individual baits separately, the use of barcodes will allow the sequencing of pooled baits while maintaining the associations between interacting pairs. This approach will increase the number of baits that can be screened per experiment and decrease the cost of screening individual baits. In addition, as the costs of next-generation sequencing experiments continue to drop, QIS-Seq promises to become a cost-effective alternative to traditional yeast two-hybrid screening approaches.

\section{Methods}

Bacterial strains and routine culture conditions

Escherichia coli and Agrobacterium tumefaciens were grown in Luria-Bertani broth, and Pseudomonas syringae was grown in King's broth (KB). Antibiotics were used at the following concentrations: for E. coli, $50 \mu \mathrm{g} / \mathrm{mL}$ kanamycin, $100 \mu \mathrm{g} / \mathrm{mL}$ ampicillin; for A. tumefaciens: $100 \mu \mathrm{g} / \mathrm{mL}$ kanamycin, $100 \mu \mathrm{g} / \mathrm{mL}$ rifamcipin; and for $P$. syringae: $50 \mu \mathrm{g} / \mathrm{mL}$ kanamycin, $50 \mu \mathrm{g} / \mathrm{mL}$ rifamcipin and $50 \mu \mathrm{g} / \mathrm{mL}$ cycloheximide.

\section{Plant growth conditions}

Arabidopsis plants were grown with $9 \mathrm{~h}$ of light $(\sim 130$ microeinsteins $\mathrm{m}^{-2} \mathrm{~s}^{-1}$ ) and $16 \mathrm{~h}$ of darkness at $22^{\circ} \mathrm{C}$ in 
Sunshine \#1 soil supplemented with 20:20:20 fertilizer. Nicotiana benthamiana plants were grown with $9 \mathrm{~h}$ of light $\left(\sim 130\right.$ microeinsteins $\left.\mathrm{m}^{-2} \mathrm{~s}^{-1}\right)$ and $16 \mathrm{~h}$ of darkness at $22^{\circ} \mathrm{C}$ in Sunshine \#1 soil supplemented with 20:20:20 fertilizer and osmocute.

\section{Cloning}

Pfu polymerase (Fermentas) was used for all cloning and all constructs were confirmed by sequencing. For the split-ubiquitin constructs, bait genes were amplified by PCR to contain an in-frame HA epitope, a polybasic region (K6 or K8) and a CAAX box, as well as appropriate unique restriction sites. The bait-HA-K6-CAAX genes were cloned into the $\mathrm{pBT} 3-\mathrm{N}$ vector (Dualsystems Biotech) using Sfil. The bait-HA-K8-CAAX genes were cloned into the pTLB-1 vector (gift of Dr. Igor Stagljar, University of Toronto) using NcoI. The orientation of each gene in the vector was confirmed.

For the split-YFP constructs, the HopZ genes or the 3' end of MLO2 were amplified by PCR to contain an inframe HA epitope and appropriate unique restriction sites. All of the genes for the split-YFP system were cloned using XhoI and StuI into pBD-nYFP or pBDcYFP. pBD-nYFP and pBD-cYFP were modified from pTA7002 [47] to add an HA tag and the N- or C-terminus of YFP between the StuI and SpeI sites. The N-terminus of YFP encompasses residues 1-155 while the Cterminus of YFP includes residues 156 to the stop codon.

The constructs used for plant infectivity assays were previously described [11]. In brief, the HopZ allele is expressed under its native promoter and contains an inframe HA tag.

\section{cDNA library}

Five week old Arabidopsis rosette leaves were infiltrated by hand with a needleless syringe with $P$. syringae $\mathrm{pv}$. tomato DC3000 (PtoDC3000), PtoDC3000 carrying AvrRpm 1 or the $\Delta$ hrcC mutant of PtoDC3000 at an optical density of $0.1\left(\sim 5 \times 10^{7} \mathrm{CFU} / \mathrm{mL}\right)$ at $600 \mathrm{~nm}$. Infiltrated leaves were harvested at $4 \mathrm{hpi}$ (PtoDC3000, PtoDC3000 carrying AvrRpm1, or PtoDC3000 $\Delta$ hrcC) or 12 hpi (PtoDC3000, PtoDC3000 $\Delta$ hrcC). Uninfiltrated leaves were harvested at $4 \mathrm{pi}$ and $12 \mathrm{hpi}$. RNA was extracted using Trizol (Invitrogen). mRNA was cloned into the pPR3-N vector (Dualsystems Biotech) using the $S f i$ sites (Norclone Biotech Laboratories, Ontario) with the NubG at the N-terminus of the prey proteins. The library contained $\sim 2.3 \times 10^{9}$ clones, with an average size of $1.2 \mathrm{kB}$ and was $90 \%$ recombinant. Amplification of the library was carried out by the semi-solid method [22]. $0.5 \mu \mathrm{L}$ of the primary library in E. coli strain DH5a was inoculated into $2 \times$ LB broth with $0.3 \%$ Seaprep agarose (FMC, Rockland) and $100 \mu \mathrm{g} / \mathrm{mL}$ ampicillin.
The inoculated cultures were then incubated in a waterice bath for 1 hour. Subsequently, the inoculated cultures were incubated at $30^{\circ} \mathrm{C}$ for 44 hours without shaking. To sequence the primary and secondary libraries, low-cycle PCR amplification was carried out with pPR3$\mathrm{N}$ vector-specific primers and a high-fidelity Taq/proofreading polymerase mix (Fermentas, Burlington). This pool of DNA was sheared and prepared for Illumina sequencing by standard methods.

\section{Yeast two-hybrid screening}

$\mathrm{HopZ1}^{\mathrm{C} / \mathrm{A}}$, HopZ1b ${ }^{\mathrm{C} / \mathrm{A}}, \mathrm{HopZ1}^{\mathrm{C} / \mathrm{A}}$, HopZ2 ${ }^{\mathrm{C} / \mathrm{A}}$, and $\mathrm{ZAR} 1^{\mathrm{CC}}$ were expressed under the weak $\mathrm{CYC} 1$ promoter in the $\mathrm{pBT}^{-\mathrm{N}}$ vector, while $\mathrm{HopZ3}^{\mathrm{C} / \mathrm{A}}$ was expressed under the strong TEF1 promoter in the pTLB-1 vector. AP-4 yeast [48] carrying the bait construct were transformed using the PEG/LiAc method. In brief, yeast carrying the bait construct were subcultured in $300 \mathrm{~mL}$ SD-Leu overnight to an optical density of 0.6 at $600 \mathrm{~nm}$. Yeast were washed twice in sterile $\mathrm{H}_{2} \mathrm{O}$ and resuspended in $1.5 \mathrm{~mL}$. Transformations were performed with $1 \mu \mathrm{g}$ of cDNA library, $200 \mu \mathrm{L}$ of yeast cells and $600 \mu \mathrm{L}$ of PEG/LiAc (50\% PEG, $120 \mathrm{mM} \mathrm{LiAc,} 10$ $\mu \mathrm{L} 10 \mathrm{mg} / \mathrm{mL}$ boiled salmon sperm DNA) by the heat shock method at $42^{\circ} \mathrm{C}$ for $45 \mathrm{~min}$. Yeast were washed twice in sterile $\mathrm{H}_{2} \mathrm{O}$ and plated on SD-LeuTrp and SDLeuTrpHis + 3-amino-1,2,4-triazole (3-AT). Interacting colonies were identified by growth on SD-LeuTrpHis + 3-AT. The appropriate amount of 3-AT was determined for each bait by testing for growth when transformed with the positive control pFur4-NubI and a lack of growth with pFur4-NubG [48]. Screening was performed until 2000 interacting colonies were identified. Colonies were restreaked twice on SD-Trp to preferentially lose the bait plasmid [10] and grown at $28^{\circ} \mathrm{C}$. Prior to plasmid isolation, colonies were restreaked onto SD-Trp and grown at $28^{\circ} \mathrm{C}$. Yeast were harvested en masse in SD-Trp and pelleted at $1000 \mathrm{~g}$ for $5 \mathrm{~min}$. The pellet ( $5 \mathrm{~g}$ ) was washed in $0.1 \mathrm{M} \mathrm{NaPO}_{4} \mathrm{pH} 7.4$ and $1.2 \mathrm{M}$ sorbitol and resuspended in $7.1 \mathrm{~mL}$ of lyticase buffer [0.1 $\mathrm{M} \mathrm{NaPO}_{4} \mathrm{pH} 7.4,1.2 \mathrm{M}$ sorbitol, $500 \mu \mathrm{L}$ lyticase (Sigma), $50 \mu \mathrm{L}$ of $10 \mathrm{mg} / \mathrm{mL}$ RNAseA]. $25 \mathrm{KU}$ of lyticase was resuspended in $0.01 \mathrm{M} \mathrm{NaPO}_{4} \mathrm{pH} 7.4$ and $50 \%$ glycerol and used immediately. Yeast were incubated in the lyticase buffer overnight at $37^{\circ} \mathrm{C}$. The Qiagen alkaline lysis spin kit was used to extract the plasmid DNA. The lyticase buffer was used instead of buffer P1. Volumes of buffers P2 and N3 were scaled up to the typical Qiagen proportions based on the volume of the resuspended pellet (1 vol lyticase buffer: 1 vol P2: 1.4 vol N3). Lysis in the P2 buffer was done for $15 \mathrm{~min}$ at room temperature and $15 \mathrm{~min}$ at $65^{\circ} \mathrm{C}$. Buffer N3 was chilled prior to use. After addition of buffer N3, the yeast were incubated on ice for $20 \mathrm{~min}$. Yeast were 
pelleted at $14000 \mathrm{rpm}$ for $30 \mathrm{~min}$ at $4^{\circ} \mathrm{C}$. The supernatant was removed and cleared again by centrifugation at $14000 \mathrm{rpm}$ for $15 \mathrm{~min}$ at $4^{\circ} \mathrm{C}$. The supernatant was loaded onto multiple Qiagen spin columns to purify the plasmid DNA. The columns were washed with buffer PB and buffer PE. Plasmid DNA was eluted with $50 \mu \mathrm{L}$ of buffer EB after a 1 min incubation. A second elution was performed with $35 \mu \mathrm{L}$ of buffer EB after a 1 min incubation. To sequence the putative interactors, lowcycle PCR amplification was carried out with pPR3-N vector-specific primers and a high-fidelity Taq/proofreading polymerase mix (Fermentas, Burlington). This pool of DNA was sheared and prepared for Illumina sequencing by standard methods.

\section{Illumina Sequencing}

Illumina sequencing was performed either with 37 cycle single reads or 72 cycle paired-end reads (Additional file 1) following the manufacturer's protocol on an Illumina GAIIx and pipelined using the GA pipeline v1.4.

\section{Bioinformatics}

Illumina reads were mapped to Arabidopsis gene models downloaded from NCBI, using a short read mapping tool novoalign (novocraft.com). From the mapping data, the number of mapped reads and the total length of mapped regions for each gene were determined with in house scripts. Read numbers per gene were further normalized as reads per million (rpm) within each sample and compared among the samples. The enrichment of a specific interactor with a bait of interest was determined by considering the number of reads obtained with the bait and luciferase and normalizing against the abundance of reads for luciferase, the bait and the library (Additional file 5). The percentage of the mapped length was calculated using length of mapped regions and the theoretical length of the gene model. Gene Ontology terms for Arabidopsis genes were downloaded from the TAIR website, and assigned to the genes in the cDNA library. Up- or down-regulation of each gene in response to biotic stress was determined from microarray data available through the CAGEF Bio-Array Resource (BAR, http://bar.utoronto.ca, [23]. Biotic stress treatments in the BAR included inoculation with virulent, avirulent and non-host $P$. syringae, inoculation with oomycetes (Botrytis cinerea, Phytophthora infestans, Golonivomyces orontii) and inoculation with elicitors of innate immunity (harpins, lipopolysaccharides, and an oomycete elicitor NPP1).

\section{Genotyping of T-DNA insertion lines}

The following T-DNA insertion lines were used: SALK_060284C (At5g20700), SALK_082464C (At4g35750), SALK_079850C (At1g11310, mlo2-7),
SALK_050191C (At1g11310, mlo2-6), SALK_024490C (At1g68440), SAIL_808_A10 (At4g00430). Genomic DNA was extracted from a leaf of 5-6 week old Arabidopsis plants. Primers were designed using the iSct feature in the SIGnAL database. Primer sequences are available upon request. PCR-based genotyping was employed to determine the homozygosity or heterozygosity of the individuals. PCR products were sequenced using Big Dye Terminator 3.1 on an ABI 3730 genetic analyzer.

\section{Infectivity assays}

For infiltration, $P$. syringae was resuspended to an optical density of $0.1\left(\sim 5 \times 10^{7} \mathrm{CFU} / \mathrm{mL}\right)$ at $600 \mathrm{~nm}$ and diluted to a concentration of $1 \times 10^{5} \mathrm{CFU} / \mathrm{mL}$ for growth curves. Plants were infiltrated by hand with a needleless syringe, as previously described [49]. Four disks $\left(1 \mathrm{~cm}^{2}\right)$ were harvested, ground in $10 \mathrm{mM} \mathrm{MgCl}_{2}$, and plated on $\mathrm{KB}$ with rifampicin and cycloheximide on days 0 and 3 for colony counting.

\section{Statistics}

For growth assays, 8-10 plants were used for day 3 counts. Significance was determined using Fisher's Protected Least Significant Difference (PLSD) on the day 3 count data. Error bars indicate one standard deviation of the mean.

\section{Agrobacterium transient expression assays and BiFC}

Five-milliliter $A$. tumefaciens GV2260 cultures were grown overnight at $28^{\circ} \mathrm{C}$ in Luria-Bertani broth with kanamycin and rifampicin. The next day, the cultures were washed twice in induction medium (50 mM MES $\mathrm{pH}$ 5.6, 0.5\% (w/v) glucose, $1.7 \mathrm{mM} \mathrm{NaH} \mathrm{PO}_{4}, 20 \mathrm{mM}$ $\mathrm{NH}_{4} \mathrm{Cl}, 1.2 \mathrm{mM} \mathrm{MgSO}, 2 \mathrm{mM} \mathrm{KCl}, 17 \mu \mathrm{M} \mathrm{FeSO} 4,70$ $\mu \mathrm{M} \mathrm{CaCl}, 200 \mu \mathrm{M}$ acetosyringone) [50], and $3.75 \mathrm{~mL}$ was inoculated into $35 \mathrm{~mL}$ fresh induction medium to grow overnight. The following day, cultures were spun down, washed twice in $10 \mathrm{mM}$ MES pH 5.6 with 200 $\mu \mathrm{M}$ acetosyringone and resuspended to an optical density of 0.4 at $600 \mathrm{~nm}$. The culture containing the MLO2 ${ }^{\Delta 1-280}$-cYFP plasmid was mixed in equal volumes with a culture containing the HopZ1c-nYFP, HopZ2nYFP or HopZ2 $2^{\text {C/A }}$-nYFP plasmid. The culture containing the MLO2 $2^{\Delta 1-280}$-nYFP plasmid was mixed in equal volumes with a culture containing the HopZ1c-cYFP, HopZ2-cYFP or HopZ2 $2^{\mathrm{C} / \mathrm{A}}$-cYFP plasmid. The underside of the leaves of 5 - to 7 -week-old $N$. benthamiana plants were infiltrated by hand with a needleless syringe. Plants were sprayed with $20 \mu \mathrm{M}$ dexamethasone (Sigma) 1-2 hours after inoculation. Sections of leaves were imaged with a Leica SP5 microscope using Leica software at 24 hours (YFP fluorescence) or 72-96 hours (BiFC) post-dexamethasone induction. 


\section{Additional material}

Additional file 1: Illumina sequencing of CDNA libraries and interactors. Table showing the prey cDNA library used for the yeast two-hybrid screening, the number of Illumina cycles, the number of quality clusters, and the number of bases for each bait or the cDNA library.

\section{Additional file 2: Characterization of the Arabidopsis cDNA library} used in this study. A. Histogram shows the number of Arabidopsis genes on log scale plotted against the length of the CDNAs present in the cDNA library. There are no genes present in the 2300-2499 or 26002699 ranges. There is one gene present in the 2500-2599 and 2700-2799 ranges. B. Histogram shows the number of genes on log scale plotted against the percent coverage of the CDNAs in the CDNA library. $\mathbf{C}$. Scatter plot of the genes present in the primary and amplified (secondary) libraries. The $\mathrm{R}^{2}$ value of 0.9567 shows a high congruence between the primary unamplified and secondary amplified libraries.

Additional file 3: Schematic of the split-ubiquitin yeast two hybrid approach. The $\mathrm{N}$-terminus of the bait protein is compromised of the LexA-VP16 transcription factor (VP16), followed by the C-terminus of ubiquitin (Cub), the bait protein of interest, an HA epitope tag, a Cterminal polybasic region (K6 or K8) and CAAX box. We added the K6 (or K8) and CAAX box sequences to non-transmembrane bait proteins in order to anchor them to membranes and minimize autoactivation. At the $\mathrm{N}$-terminus of the prey proteins is the $\mathrm{N}$-terminal half of ubiquitin with an isoleucine to glycine mutation, which reduces non-specific association with Cub (NubG) [21]. The prey proteins may be membraneassociated or cytoplasmic (not shown). In the case of interaction between a bait and prey, the Cub and Nub portions of ubiquitin are brought into close proximity and reconstitute the full ubiquitin protein. A ubiquitin-specific protease (the "blades") cleaves the VP16 transcription factor, allowing it to translocate to the nucleus and activate the HIS reporter gene.

Additional file 4: Bait and prey vectors used in QIS-Seq. The bait:HA: K6:CAAX was cloned into the Sfil sites of the pBT3-N vector, in frame with an N-terminal LexA-VP16 (VP16) and the C-terminus of ubiquitin (Cub). Bait protein expression is driven by the weak CYC1 promoter. Stronger bait expression was achieved by cloning the bait:HA:K8:CAAX into the Ncol site of the pTLB-1 vector, in frame with an N-terminal VP16 and Cub (not shown). The prey cDNAs were cloned into the Sfil sites of the pPR3-N vector, in frame with an N-terminal ubiquitin (the N-terminus of ubiquitin with an isoleucine to glycine mutation, NubG) [21]. Prey protein expression is driven by the weak CYC1 promoter.

Additional file 5: Rank list of top interactors with HopZ2 and their enrichment with other HopZ alleles, an unrelated T3SE HopF2 and ZAR1. Table indicates the percentage enrichment with each tested bait for the top HopZ2 interactors in Arabidopsis.

Additional file 6: Disruption of $M L O 2$ compromises $P$. syringae virulence. A. The virulent pathogen PtoDC3000 was pressure-infiltrated into the leaves of Arabidopsis Col-0 or the mlo2-6 T-DNA insertion line. * indicates significant difference from Col-0 by Fisher's PLSD test. Error bars indicate one standard deviation of the mean. $\mathbf{B}$. The virulent pathogen PtoDC3000 was pressure-infiltrated into the leaves of Arabidopsis Col-0 or the mlo2-11 (pmr2-1) point mutant. Error bars indicate one standard deviation of the mean

\section{Additional file 7: HopZ2 interacts with $\mathrm{MLO}^{\Delta 1-280}$ in planta by} bimolecular fluorescence microscopy and MLO ${ }^{\Delta 1-280}$ localizes to a reticulate network. A. Agrobacterium carrying HopZ2::nYFP or MLO2 ${ }^{\Delta 1}$ ${ }^{280 .: C Y F P}$ were mixed at equivalent optical densities and pressureinfiltrated into the leaves of $\mathrm{N}$. benthamiana. Expression of the proteins was induced by $20 \mu \mathrm{M}$ dexamethasone. Sections of leaf tissue were imaged with a Leica SP5 confocal scanning microscope 72-96 hours post-induction. The scale bar indicates $100 \mu \mathrm{m}$. B. Agrobacterium carrying $\mathrm{MLO}^{\triangle 1-280}:$ Y.YFP was pressure-infiltrated into the leaves of $\mathrm{N}$. benthamiana. Expression of the proteins was induced by $20 \mu \mathrm{M}$ dexamethasone. Sections of leaf tissue were imaged with a Leica SP5 confocal scanning microscope 24 hours post-induction. The scale bar indicates $100 \mu \mathrm{m}$. Fluorescence is observed in a reticular pattern reminiscent of the endoplasmic reticulum.

\section{Abbreviations}

ETI: effector-triggered immunity; MLO: powdery mildew resistance gene O; Pci: Pseudomonas syringae pv. cilantro; Pto: Pseudomonas syringae pv. tomato; R: resistance; RIN4: RPM1-interacting protein 4; T3SE: type III secreted effector; T3SS: type III secretion system; ZAR: HopZ-activated resistance

\section{Acknowledgements}

We are grateful to Mike Wilton for infiltrating the plants, preparing the RNA used in the CDNA library construction and sharing the QIS-Seq data for HopF2pto; Dr. Igor Stagljar for split-ubiquitin yeast two-hybrid vectors and yeast strain; the Arabidopsis Biological Research Center (ABRC) for providing seed stocks. This research was supported by NSERC discovery grants to DD and DSG a Canada Research Chair in Plant-Microbe Systems Biology (DD) or Comparative Genomics (D.S.G.); the Centre for the Analysis of Genome Evolution and Function (DD and DSG); and an NSERC undergraduate research award (JW)

\section{Author details}

'Department of Cell and Systems Biology, University of Toronto, Toronto, ON, M5S 3B2, Canada. ${ }^{2}$ Centre for the Analysis of Genome Evolution and Function, University of Toronto, Toronto, ON, M5S 3B2, Canada. ${ }^{3}$ Plant Gene Expression Center, USDA, 800 Buchanan St., Albany, CA, 94710, USA.

\section{Authors' contributions}

$J D L, D D$ and DSG conceived the experiment; JDL performed the experiments; JW and RF assisted with the split-ubiquitin yeast two-hybrid screening; Y.G. performed the bioinformatics analysis; PF ran the Illumina GAll; HN analyzed microarray data from the BAR; PW provided critical input for GAll sequencing; JDL, YG, DD and DSG analyzed the data; JDL, DD and DSG wrote the manuscript. All authors read and approved the final manuscript.

Received: 16 September 2011 Accepted: 9 January 2012

Published: 9 January 2012

\section{References}

1. Espinosa A, Alfano JR: Disabling surveillance: bacterial type III secretion system effectors that suppress innate immunity. Cell Microbiol 2004, 6:1027-1040.

2. Grant SR, Fisher EJ, Chang JH, Mole BM, Dangl JL: Subterfuge and manipulation: type III effector proteins of phytopathogenic bacteria. Annu Rev Microbiol 2006, 60:425-449.

3. Block A, Li GY, Fu ZQ, Alfano JR: Phytopathogen type III effector weaponry and their plant targets. Curr Opin Plant Biol 2008, 11:396-403.

4. Boller T, He SY: Innate immunity in plants: an arms race between pattern recognition receptors in plants and effectors in microbial pathogens. Science 2009, 324:742-744.

5. Lewis JD, Desveaux D, Guttman DS: The targeting of plant cellular systems by injected type III effector proteins. Semin Cell Dev Biol 2009, 20:1055-1063.

6. Dangl JL, Jones JDG: Plant pathogens and integrated defence responses to infection. Nature 2001, 411:826-833.

7. Jones JDG, Dangl JL: The plant immune system. Nature 2006, 444:323-329.

8. McCann HC, Guttman DS: Evolution of the type III secretion system and its effectors in plant-microbe interactions. New Phytol 2008, 177:33-47.

9. Ma WB, Dong FFT, Stavrinides J, Guttman DS: Type III effector diversification via both pathoadaptation and horizontal transfer in response to a coevolutionary arms race. PLoS Genet 2006, 2:e209.

10. Lewis JD, Lee A, Ma W, Zhou H, Guttman DS, Desveaux D: The YopJ superfamily in plant-associated bacteria. Mol Plant Path 2011, 12:928-937.

11. Lewis JD, Abada W, Ma WB, Guttman DS, Desveaux D: The HopZ family of Pseudomonas syringae type III effectors require myristoylation for virulence and avirulence functions in Arabidopsis thaliana. J Bacteriol 2008, 190:2880-2891.

12. Lewis JD, Wu R, Guttman DS, Desveaux D: Allele-specific virulence attenuation of the Pseudomonas syringae HopZ1a type III effector via the Arabidopsis ZAR1 resistance protein. PLoS Genet 2010, 6:e1000894. 
13. Vinatzer BA, Teitzel GM, Lee MW, Jelenska J, Hotton S, Fairfax K, Jenrette J, Greenberg JT: The type III effector repertoire of Pseudomonas syringae pv. syringae B728a and its role in survival and disease on host and nonhost plants. Mol Microbiol 2006, 62:26-44.

14. Fields S, Song OK: A novel genetic system to detect protein-protein interactions. Nature 1989, 340:245-246.

15. Walhout AJM, Vidal M: High-throughput yeast two-hybrid assays for large-scale protein interaction manning. Methods 2001, 24:297-306.

16. Yu HY, Braun P, Yildirim MA, Lemmens I, Venkatesan K, Sahalie J, HirozaneKishikawa T, Gebreab F, Li N, Simonis N, Hao T, Rual JF, Dricot A, Vazquez A, Murray RR, Simon C, Tardivo L, Tam S, Svrzikapa N, Fan CY, de Smet AS, Motyl A, Hudson ME, Park J, Xin XF, Cusick ME, Moore T, Boone C, Synder M, Roth RP, Barabasi AL, Tavernier J, Hill DE, Vidal M: High-quality binary protein interaction map of the yeast interactome network. Science 2008, 322:104-110.

17. Dreze M, Monachello D, Lurin C, Cusick ME, Hill DE, Vidal M, Braun P: Highquality binary interactome mapping. Methods Enzymol 2010, 470:281-315.

18. Venkatesan K, Rual JF, Vazquez A, Stelzl U, Lemmens I, Hirozane-Kishikawa T, Hao T, Zenkner M, Xin XF, Goh Kl, Yildirim MA, Simonis N, Heinzmann K, Gebreab F, Sahalie JM, Cevik S, Simon C, de Smet AS, Dann E, Smolyar A, Vinayagam A, Yu HY, Szeto D, Borick H, Dricot A, Klitgord N, Murray RR, Lin C, Lalowski M, Timm J, Rau K, Boone C, Braun P, Cusick ME, Roth FP, Hill DE, Tavernier J, Wanker EE, Barabasi AL, Vidal M: An empirical framework for binary interactome mapping. Nat Methods 2009, 6:83-90.

19. Yu HY, Tardivo L, Tam S, Weiner E, Gebreab F, Fan C, Svrzikapa N, HirozaneKishikawa T, Rietman E, Yang X, Sahalie J, Salehi-Ashtiani K, Hao T, Cusick ME, Hill DE, Roth RP, Braun P, Vidal M: Next-generation sequencing to generate interactome datasets. 2011, 8:478-480.

20. Zhou HB, Morgan RL, Guttman DS, Ma WB: Allelic variants of the Pseudomonas syringae type III effector HopZ1 are differentially recognized by plant resistance systems. Mol Plant-Microbe Interact 2009, 22:176-189.

21. Stagljar I, Korostensky C, Johnsson N, te Heesen S: A genetic system based on split-ubiquitin for the analysis of interactions between membrane proteins in vivo. Proc Natl Acad Sci USA 1998, 95:5187-5192.

22. Kriegler M: Expression cloning. Gene transfer and expression: a laboratory manual New York: Stockton Press; 1990, 131-132.

23. Toufighi K, Brady SM, Austin R, Ly E, Provart NJ: The botany array resource: e-Northerns, expression angling, and promoter analyses. Plant J 2005, 43:153-163.

24. Hancock JF, Paterson H, Marshall CJ: A polybasic domain or palmitoylation is required in addition to the CAAX motif to localize p21 ras to the plasma membrane. Cell 1990, 63:133-139.

25. Yeung T, Gilbert GE, Shi J, Silvius J, Kapus A, Grinstein S: Membrane phosphatidylserine regulates surface charge and protein localization. Science 2008, 319:210-213.

26. Overall CM, Tam EM, Kappelhoff R, Connor A, Ewart T, Morrison CJ, Puente X, Lopez-Otin C, Seth A: Protease degradomics: mass spectrometry discovery of protease substrates and the CLIP-CHIP, a dedicated DNA microarray of all human proteases and inhibitors. Biol Chem 2004, 385:493-504.

27. Blanchetot C, Chagnon M, Dube N, Halle A, Tremblay ML: Substratetrapping techniques in the identification of cellular PTP targets. Methods 2005, 35:44-53.

28. Zhang $Z$, MooYoung $M$, Chisti Y: Plasmid stability in recombinant Saccharomyces cerevisiae. Biotechnol Adv 1996, 14:401-435.

29. Vogel J, Somerville S: Isolation and characterization of powdery mildewresistant Arabidopsis mutants. Proc Natl Acad Sci USA 2000, 97:1897-1902.

30. Consonni C, Humphry ME, Hartmann HA, Livaja M, Durner J, Westphal L, Vogel J, Lipka V, Kemmerling B, Schulze-Lefert P, Somerville SC, Panstruga R: Conserved requirement for a plant host cell protein in powdery mildew pathogenesis. Nature Genet 2006, 38:716-720.

31. Dodds PN, Rathjen JP: Plant immunity: towards an integrated view of plant-pathogen interactions. Nat Rev Genet 2010, 11:539-548.

32. Block A, Alfano JR: Plant targets for Pseudomonas syringae type III effectors: virulence targets or guarded decoys? Curr Opin Microbiol 2011 $14: 39-46$.

33. Devoto A, Piffanelli P, Nilsson I, Wallin E, Panstruga R, von Heijne G, Schulze-Lefert P: Topology, subcellular localization, and sequence diversity of the Mlo family in plants. J Biol Chem 1999, 274:34993-35004.
34. Buschges $R$, Hollricher $K$, Panstruga $R$, Simons $G$, Wolter M, Frijters $A$, van Daelen R, van der Lee T, Diergaarde P, Groenendijk J, Topsch S, Vos P, Salamini F, Schulze-Lefert P: The barley Mlo gene: a novel control element of plant pathogen resistance. Cell 1997, 88:695-705.

35. Humphry M, Consonni C, Panstruga R: mlo-based powdery mildew immunity: silver bullet or simply non-host resistance? Mol Plant Pathol 2006, 7:605-610.

36. Bhat RA, Miklis M, Schmelzer E, Schulze-Lefert P, Panstruga R: Recruitment and interaction dynamics of plant penetration resistance components in a plasma membrane microdomain. Proc Natl Acad Sci USA 2005, 102:3135-3140.

37. Collins NC, Thordal-Christensen H, Lipka V, Bau S, Kombrink E, Qiu JL, Huckelhoven R, Stein M, Freialdenhoven A, Somerville SC, Schulze-Lefert P. SNARE-protein-mediated disease resistance at the plant cell wall. Nature 2003, 425:973-977

38. Assaad FF, Qiu JL, Youngs H, Ehrhardt D, Zimmerli L, Kalde M, Wanner G, Peck SC, Edwards H, Ramonell K, Somerville SC, Thordal-Christensen H: The PEN1 syntaxin defines a novel cellular compartment upon fungal attack and is required for the timely assembly of papillae. Mol Biol Cell 2004, 15:5118-5129.

39. Meyer D, Pajonk S, Micali C, O'Connell R, Schulze-Lefert P: Extracellular transport and integration of plant secretory proteins into pathogeninduced cell wall compartments. Plant J 2009, 57:986-999.

40. Kim HS, Desveaux D, Singer AU, Patel P, Sondek J, Dangl JL: The Pseudomonas syringae effector AvrRpt2 cleaves its C-terminally acylated target, RIN4, from Arabidopsis membranes to block RPM1 activation. Proc Natl Acad Sci USA 2005, 102:6496-6501.

41. Mackey D, Holt BF, Wiig A, Dangl JL: RIN4 interacts with Pseudomonas syringae type III effector molecules and is required for RPM1-mediated resistance in Arabidopsis. Cell 2002, 108:743-754.

42. Axtell MJ, Chisholm ST, Dahlbeck D, Staskawicz BJ: Genetic and molecular evidence that the Pseudomonas syringae type III effector protein AvrRpt2 is a cysteine protease. Mol Microbiol 2003, 49:1537-1546.

43. Mackey D, Belkhadir Y, Alonso JM, Ecker JR, Dangl JL: Arabidopsis RIN4 is a target of the type III virulence effector AvrRpt2 and modulates RPS2mediated resistance. Cell 2003, 112:379-389.

44. Wilton M, Subramaniam R, Elmore J, Felsensteiner C, Coaker G, Desveaux D: The type III effector HopF2(Pto) targets Arabidopsis RIN4 protein to promote Pseudomonas syringae virulence. Proc Natl Acad Sci USA 2010, 107:2349-2354.

45. Nomura K, DebRoy S, Lee YH, Pumplin N, Jones J, He SY: A bacterial virulence protein suppresses host innate immunity to cause plant disease. Science 2006, 313:220-223.

46. Nimchuk Z, Marois E, Kjemtrup S, Leister RT, Katagiri F, Dangl JL: Eukaryotic fatty acylation drives plasma membrane targeting and enhances function of several type III effector proteins from Pseudomonas syringae. Cell 2000, 101:353-363.

47. Aoyama T, Chua NH: A glucocorticoid-mediated transcriptional induction system in transgenic plants. Plant J 1997, 11:605-612.

48. Iyer K, Burkle L, Auerback D, Thaminy S, Dinkel M, Engels K, Stagljar I: Utilizing the split-ubiquitin membrane yeast two-hybrid system to identify protein-protein interactions of integral membrane proteins. Sci STKE 2005, 2005:13.

49. Katagiri F, Thilmony R, He SY: The Arabidopsis thaliana-Pseudomonas syringae interaction. In The Arabidopsis Book doi/101199/tab 0039. Edited by: Somerville CR, Meyerowitz EM. Rockville: American Society of Plant Biologists; 2002:.

50. Sessa G, D'Ascenzo M, Martin GB: Thr38 and Ser198 are Pto autophosphorylation sites required for the AvrPto-Pto-mediated hypersensitive response. Embo J 2000, 19:2257-2269.

doi:10.1186/1471-2164-13-8

Cite this article as: Lewis et al:: Quantitative Interactor Screening with next-generation Sequencing (QIS-Seq) identifies Arabidopsis thaliana MLO2 as a target of the Pseudomonas syringae type III effector HopZ2. BMC Genomics 2012 13:8. 